\title{
SCREENING OF ANTIBIOTIC PRODUCING MICROORGANISM FROM RHIZOSPHERE SOIL AND THEIR ANTIBIOTIC PRODUCTION AND CHARACTERIZATION
}

${ }^{1}$ Vishwambhar Vishnu Bhandare and ${ }^{2}$ Sandip Mahadev Chavre

Center for Bioinformatics, Pondicherry University, Pondicherry, India 605014

${ }^{2}$ Department of Biotechnology, KIT's College of engineering, Shivaji University, Kolhapur Email: vishwayogi@gmail.com

\begin{abstract}
:
Rhizosphere soil samples were preferred as it contains most of the prospective antibiotic producers. In an attempt to screen out new potent antibiotic producers from soil, Rhizobium species was isolated. Antibiotic produced by shake flask culture is found to be effective against both gram positive and gram negative organisms. This product was found to be very promising antibiotics when assayed biologically. UV treatment showed positive effect on antibiotic production. The molecular structure of antibiotic was identified by using advanced analytical techniques like UV Visible spectroscopy, FTIR, GCMS, NMR spectroscopy.
\end{abstract}

\section{INTRODUCTION:}

Almost all the bacteria, plant and animal cells produce secondary metabolites. The bacterium is commercially important for human and veterinary medicine because it is one of the main producers of antibiotics. Microbial secondary metabolites include antibiotics, pigments, toxins, effectors of ecological competition and symbiosis, pheromones, enzyme inhibitors, immunomodulating agents, receptor antagonists and agonists, pesticides, antitumor agents and growth promoters of animals and plants. Rhizosphere soil contains most of the prospective antibiotic producers. Most of the pathogenic organisms becoming resistant to antibiotics available commercially, So there is a great need to look for a potent broad range antibiotic from natural resources. Thus we focused to screen the antibiotic producers from Rhizosphere soil sample, their antibiotic production and characterization of antibiotic using advanced techniques.

\section{METHODS AND RESULTS:}

Garden soil was used for screening

Primary screening for Antibiotic Producers:

Crowded plate technique was used to screen antibiotic producers from Rhizosphere soil sample. After incubation at room temperature for $24-48 \mathrm{hrs}$, plate showed crowded growth showing zone of inhibition surrounding few colonies. Zones were confirmed by Wilkins overlay method.

Antibiotic Spectrum of the isolate:

Trypticase soy agar was used to perform this assay. Test organisms used were Escherichia coli, Staphylococcus aureus, Bacillus subtilis, Bacillus cereus and Streptococcus pneumoniae.

\section{Test Organisms:}

\begin{tabular}{|c|c|c|}
\hline Organisms & Gram nature & Zone of Inhibitions \\
\hline S.aureus & Gram positive & positive \\
\hline B.subtilis & Gram positive & positive \\
\hline B.cereus & Gram positive & Negative \\
\hline E.coli & Gram negative & Positive \\
\hline S. pneumoniae & Gram positive & Positive \\
\hline
\end{tabular}

\section{Bacteriological studies of the isolate:}

\begin{tabular}{|c|c|}
\hline GRAM NATURE & MOTILITY \\
\hline Gram negative & Actively motile \\
\hline
\end{tabular}

\section{Colony Characteristics:}

\begin{tabular}{|c|c|c|c|c|c|c|}
\hline Size & Shape & Color & Margin & Elevation & Opacity & Consistency \\
\hline $4 \mathrm{~mm}$ & Circular & White & Irregular & Flat & Opaque & Moist \\
\hline
\end{tabular}

\section{Biochemical tests:}

\begin{tabular}{|c|c|}
\hline Test & Observation \\
\hline Catalase & + \\
\hline Starch agar & + \\
\hline Urease & + \\
\hline Milk agar & + \\
\hline Gelatin agar & + \\
\hline Oxidase & \\
\hline Carbohydrate tests: & - \\
\hline Dextrose & + \\
\hline Lactose & - \\
\hline Sucrose & + \\
\hline Sorbitol & - \\
\hline Arabinose & + \\
\hline Maltose & + \\
\hline Mannitol & + \\
\hline Trehalose & + \\
\hline Fructose & + \\
\hline Mannose & + \\
\hline Cellobiose & \\
\hline & \\
\hline
\end{tabular}

These observations were tallied with results given in the Bergey's Manual of Systematic Bacteriology Volume I. Thus the isolated colony from the soil sample belongs to Rhizobium sps

\section{Production of antibiotic by shake flask culture:}

Inoculum preparation:

Inoculum was prepared using 24 hrs old actively growing cultures. It was standardized so as to contain $10^{6}$ cells $/ \mathrm{ml}$. $\underline{\text { Medium: }}$

$\begin{array}{lr}\text { Tryptone } & 5.0 \mathrm{gm} \\ \mathrm{K}_{2} \mathrm{HPO}_{4} & 2.0 \mathrm{gm} \\ \mathrm{NaCl} & 2.0 \mathrm{gm} \\ \mathrm{FeSO}_{4} \cdot 7 \mathrm{H}_{2} \mathrm{O} & 5.0 \mathrm{gm} \\ \mathrm{Glucose}_{\mathrm{d}} & 10.0 \mathrm{gm} \\ \mathrm{d} / \mathrm{w} & 1000 \mathrm{ml}\end{array}$

Culture conditions:

$5 \%$ of above inoculum was added to $100 \mathrm{ml}$ of culture media taken in $500 \mathrm{ml}$ flasks in duplicates. Incubated in orbital incubator shaker adjusted at room temperature and $100 \mathrm{rpm}$ for 3-5 days. $\mathrm{pH}$ of broth was maintained in between 6.9-7.1

\section{Extraction and Bioassay of Antibiotic:}

Extracted antibiotic was used for Bioassay and structural analysis.

\section{Bioassay:}

\begin{tabular}{|c|c|}
\hline $\begin{array}{c}\text { Concentration of antibiotic } \\
(\%)\end{array}$ & Zone diameter (cm) \\
\hline 10 & 1.7 \\
\hline 20 & 2.1 \\
\hline 30 & 2.4 \\
\hline 40 & 2.5 \\
\hline 50 & 2.9 \\
\hline 60 & 3.1 \\
\hline
\end{tabular}

\section{Mutation treatment:}

Antibiotic extracted from UV mutated bacteria showed higher antibacterial activity

\section{Structural analysis of Antibiotic:}

The molecular nature of the purified antimicrobial product was determined by using analytical techniques like UV visible spectroscopy, FTIR, GCMS and NMR etc.

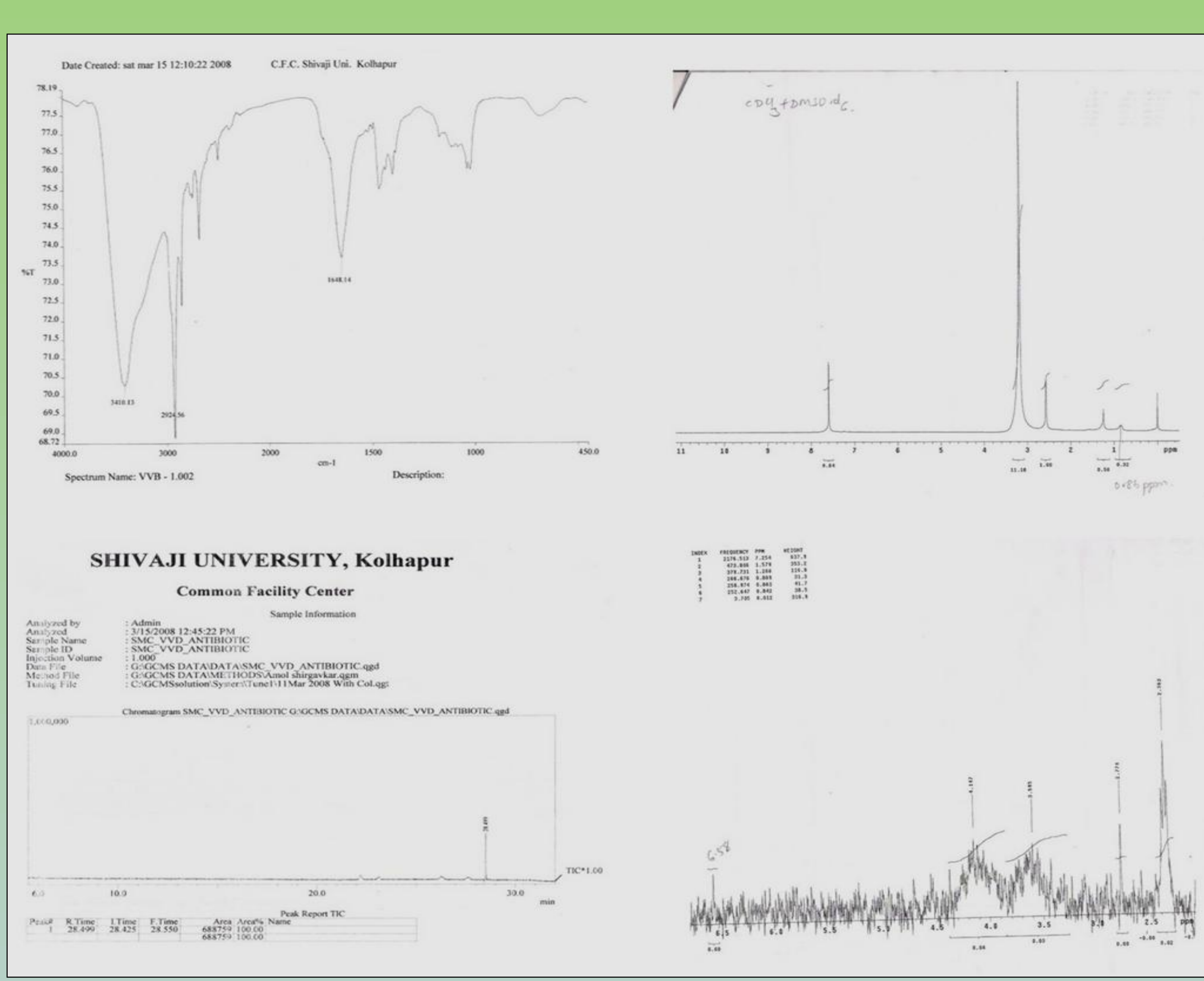

Thus, using above analytical data's the structure of extracted antibiotic was drawn as shown below

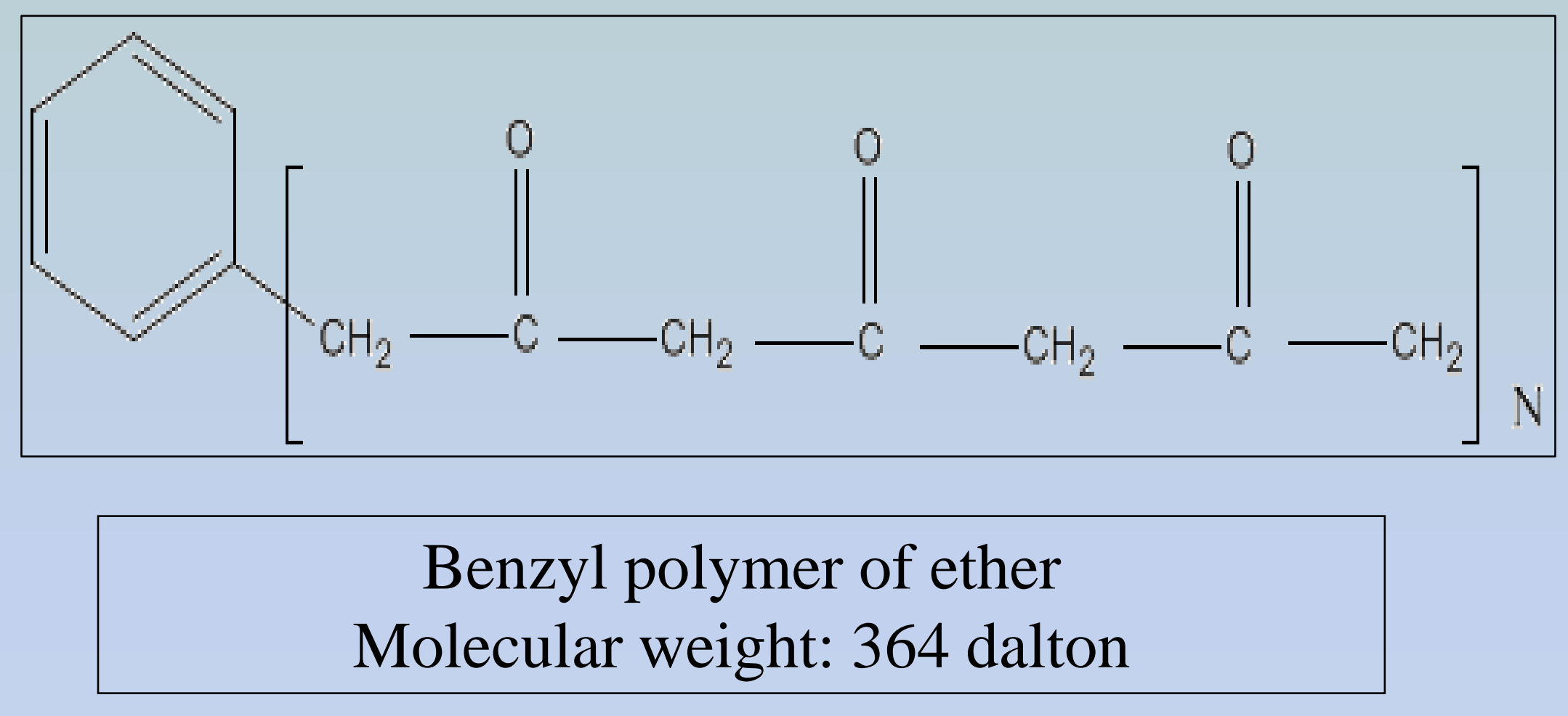

\section{CONCLUSIONS:}

-The antibiotic producers was screened from rhizosphere soil samples

-Bacteriological studies have shown that this organism belongs to the Rhizobium sps In vitro studies for antimicrobial spectrum showed that, it is effective against both gram positive and negative organisms

-Antibiotic produced using shake flask culture was found to be very promising when assayed biologically

-Probable antibiotic structure was determined using analytical techniques, Thus, this antibiotic belongs to the class Aromatic compounds
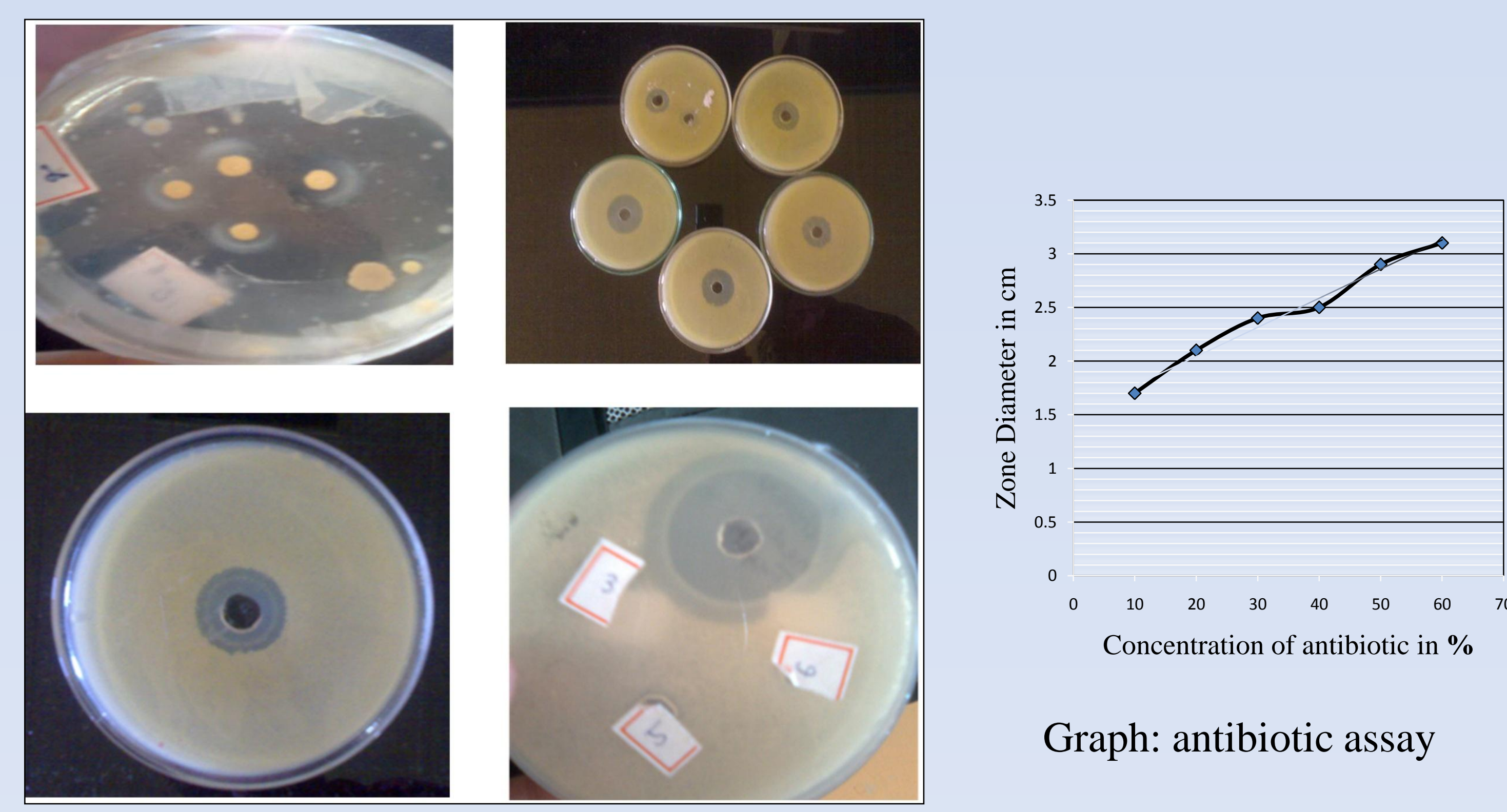

Fig.1 Primary screening Fig. 2 Bioassay of antibiotic Fig. 3 Non mutated sample Fig.4 Mutated sample 